\title{
A importância do médico pediatra na promoção da saúde bucal*
}

\section{The importance of the pediatrician in oral health care promotion}

\author{
Mariângela M. S. Schalka e Célia R. M. D. Rodrigues \\ Departamento de Ortodontia e Odotopediatria da Faculdade de Odontologia da Universidade de \\ São Paulo. São Paulo, SP - Brasil
}

\section{Resumo}

Objetivou-se realizar avaliação da conduta preventiva em relação à saúde bucal exercida por médicos pediatras da cidade de São José dos Campos-SP, Brasil. A análise foi feita através das respostas a um questionário descritivo entregue a 85 pediatras da cidade. Obteve-se um retorno de $48(56,4 \%)$. O questionário abordou aspectos relativos a amamentação, dieta, higiene bucal, uso da chupeta e do flúor e encaminhamento ao dentista. A análise dos resultados mostrou que a frequiência das orientações a respeito dessas condutas preventivas aos pacientes foi baixa. Concluiu-se ser necessário um esforço maior dos profissionais, médicos e dentistas, de promover a melhoria da saúde bucal dos pacientes infantis.

Cárie dentária, prevenção e controle. Pediatria, recursos humanos. Educação em saúde bucal.

\begin{abstract}
The degree to which the pediatrician's knowledge might contribute to preventive dentistry is investigated. Questionnaires concerning aspects such as breastfeeding, diet, pacifier use, fluoride use, oral hygiene and the recommended moment for the first dental visit were sent to a random sample of 85 pediatricians in S. José dos Campos. Answers were received from 48 $(56.4 \%)$ of them. Data showed that orientation about preventive dentistry was not a common procedure among the majority of the pediatricians, suggesting that better integration between physician and dentist is necessary if children are to grow up with better general and dental health.
\end{abstract}

Dental caries, prevention and control. Pediatrics, menpower. Health education, dental.

* Trabalho apresentado na XI Reunião da Sociedade Brasileira de Pesquisas Odontológicas, Águas de São Pedro, 1994.

Correspondência para / Correspondence to: Mariângela Milena Santos Schalka - Rua Diana, 863 Ap. 72-C - Perdizes - 05019-000 São Paulo, SP -

Brasil.E-mail: pmari@ spider.usp.br

Edição subvencionada pela FAPESP. Processo 95/2290-6.

Recebido em 14.2.1995. Aprovado em 11.12.1995. 


\section{INTRODUÇÃO}

A odontologia vem se voltando atualmente para $o$ atendimento de bebês, tentando instituir precocemente medidas educativas e preventivas. Esta tendência tem se fortalecido baseada nos dados existentes na literatura que mostram que a cárie dental em crianças pode se iniciar muito cedo e que a sua prevalência tende a aumentar com a idade.

No Brasil, em 1985, Walter e col..$^{34}$ revelaram que, de 0 a 12 meses, 23,53\% das crianças em Londrina apresentavam lesões de cárie, chegando a $62,96 \%$ na idade de 25 a 30 meses. Concluindo seu estudo, os autores afirmam que os hábitos alimentares inadequados são os principais responsáveis pela ocorrência de lesões de cárie nos primeiros anos de vida. Fraiz ${ }^{11}$ (1993), em um estudo sobre os hábitos de aleitamento e do consumo de açúcar em crianças menores que 3 anos, observou que as crianças entram em contato com açúcar precocemente, sendo que para $61,7 \%$ delas o primeiro contato ocorreu antes de completar um mês de idade, principalmente com o uso de chá. Até próximo da época de erupção do primeiro dente (mais ou menos aos 8 meses), 95,6\% das crianças já haviam consumido açúcar.

A cárie dental é uma doença infecciosa multifatorial, cuja etiologia baseia-se na presença da placa bacteriana ${ }^{17}$. Na formação da placa cariogênica, um dos principais microrganismo é o Streptococcus mutans $^{6,14,31}$. Sabendo que a cárie é uma doença infecciosa, Brown e col. ${ }^{6}$ (1985) discutem a quantidade de S.mutans da mãe e sua relação com o risco de cárie do filho, concluindo que os níveis salivares de S. mutans da mãe e da criança estão intimamente ligados e que quanto maior for o nível materno, mais rápido se dá a contaminação do filho. Isto pode ocorrer principalmente por gotículas salivares (beijo) ou pelo uso em comum de talheres e copos.

A respeito deste assunto surgem algumas questões: Quando começar a prevenção? Os dentes decíduos são importantes? Em que época deve ser a primeira visita ao dentista?

Autores como Greene ${ }^{15}$ (1973), Elvey e Hewie ${ }^{9}$ (1982), Gleiser e Czlusniak ${ }^{13}$ (1984) indicam a primeira visita ao dentista somente aos 2-3 anos, enquanto a Academia Americana de Odontopediatria recomenda que esta visita seja por volta dos 12 meses de idade ${ }^{16}$.

No Brasil, os trabalhos de Walter e col. ${ }^{34}$, na "Bebê-Clínica da Universidade Estadual de Londrina", visam a conscientizar os pais, através da divulgação científica, do quanto é importante cuidar da saúde bucal dos bebês dentro do contexto de saúde geral, o mais precocemente possível e antes dos seis meses de idade. Com este enfoque a prevenção da incidência da cárie no primeiro ano de vida é de $95,5 \%$. Se o início desses cuidados ocorrer depois de 12 meses, o índice cai para 71,5\% ${ }^{33}$.

Não obstante esses dados, observa-se que a dentição decídua, por possuir como característica principal a transitoriedade, tem seu valor subestimado e o tratamento negligenciado, e que pouca importância é dada aos aspectos preventivos da doença-cárie ${ }^{15}$.

É sabido que tudo que se aprende nos primeiros anos de vida, tanto em relação à saúde geral quanto à saúde bucal, fornece bases para uma boa saúde nas idades subseqüentes, especialmente se o exemplo se encontra dentro de casa. Junta-se a isto o fato de que a prevenção primária é o ideal tanto pelo lado biológico como pelo econômico ${ }^{15}$.

Dentro do contexto socioeconômico e cultural de um país desenvolvido como os EUA, observa-se que $90 \%$ das crianças menores que 5 anos já foram examinadas por um médico com uma média de 7 consultas anuais, enquanto que apenas $14,3 \%$ destas mesmas crianças foram consultadas por um dentista ${ }^{7}$.

No Brasil, onde apenas $5 \%$ da população tem acesso a um dentista particular ${ }^{26}$, estes dados vêm reforçar a idéia de que o médico tem papel fundamental nas primeiras orientações sobre a saúde bucal (em especial quanto à prevenção da cárie de mamadeira - causada por hábitos inadequados como adormecer mamando) 1, 7,9,23.

Ao se estudar esses dados outras questões surgem. Não poderia o médico pediatra dar orientações sobre saúde bucal? — Ele tem conhecimento suficiente para isto? - O que é importante que ele saiba? Há portanto uma necessidade de maior integração entre a odontologia e a medicina pediátrica para que esses profissionais estejam aptos a realizar algumas avaliações, dar instruções de dieta e higiene bucal, prescrever flúor se necessário e encaminhar o paciente ao cirurgião dentista, em idade adequada ${ }^{23}$.

O presente trabalho objetivou fazer uma primeira avaliação das condutas dos médicos pediatras em relação às orientações que possam promover a saúde bucal.

\section{MATERIAL E MÉTODO}

Para o presente estudo foi escolhida uma população de 120 médicos pediatras da cidade de São José dos Campos - SP, selecionados a partir das fontes consultadas Associação Paulista de Medicina de São José dos Campos, lista telefônica e catálogo de convênios médicos. A essa população foram distribuídos questionários num só dia, com prazo de uma semana para retorno; somente 85 
puderam ser localizados. Foi obtido um retorno de 48 $(56,4 \%)$, semelhante ao de Koranyi e col. ${ }^{21}$ (1991).

$\mathrm{Na}$ primeira parte do questionário havia perguntas de ordem pessoal, como sexo, tempo de formado, se teve aprendizado, e onde, sobre odontologia preventiva (graduação, pós-graduação, residência ou extra curricular) e se exercia atividade acadêmica. Na segunda parte, mais específica, foi perguntado qual seria a orientação dada aos pacientes quanto aos itens: amamentação, dieta, higiene bucal, flúor, uso de chupeta e encaminhamento ao dentista.

As perguntas eram abertas, descritivas e não em forma de testes, procurando-se minimizar a indução nas respostas.

\section{RESULTADOS E DISCUSSÃO}

Como já foi comentado na introdução existe uma concordância entre vários autores quanto à necessidade de interação entre as áreas médica e odontológica ${ }^{7,9,19,23}$. Os dados citados na introdução justificam a preocupação em se verificar o papel que o médico vem exercendo em relação a orientação de seus pacientes, uma vez que sua conduta poderia evitar a morbidade resultante dos problemas dentários, como já foi salientado por Elvey e Hewie ${ }^{9}$ (1982) e Miller e Rosenstein ${ }^{23}$ (1982).

O profissional médico poderia ter conhecimentos básicos do desenvolvimento da dentição, de orientações quanto a higiene bucal, de dieta e da época de encaminhamento ao dentista ${ }^{1,11,23}$. Isto seria de grande valia, pois raramente a criança vai ao dentista antes do primeiro ano de vida, época em que se instalam alguns dos principais hábitos alimentares, de higiene e possíveis hábitos nocivos em virtude de sucção incorreta.

Os questionários foram respondidos em número igual por mulheres e homens, 24 cada. Quanto ao tempo de exercício da profissão, $6,2 \%$ estavam formados há menos de 5 anos; $25 \%$ entre $5-10$ anos; $25 \%$ entre $10-15$ anos e $43,7 \%$ há mais de 15 anos. Não houve predominância da freqüência de condutas preventivas em relação ao tempo de exercício profissional.
Em relação ao aprendizado sobre odontologia preventiva, $54,6 \%$ dos profissionais responderam que nunca tiveram qualquer informação, $14,5 \%$ relataram ter recebido orientações durante o curso de graduação; $20,8 \%$ durante a residência pediátrica e $22,9 \%$ em cursos extracurriculares, tendo ocorrido uma, ou mais, resposta por profissional.

Quanto às orientações dos médicos aos seus pacientes e responsáveis, a primeira questão refere-se aos hábitos de amamentação, por serem estes considerados de grande importância no desenvolvimento das lesões de cárie ${ }^{8,13,14,20,21,22,27,28,34}$.

Todos os profissionais estudados ressaltaram a importância do aleitamento materno durante 6 meses pelo menos, sendo que a mamadeira é geralmente indicada e utilizada complementando o aleitamento ou em sequiência a este. Apenas $6,2 \%$ relataram evitar seu uso quando possível, passando direto ao copo na época do desmame.

No tópico sobre aleitamento, de acordo com a Tabela 1, 43,7\% dos profissionais fizeram alguma recomendação de caráter preventivo em relação à saúde bucal, totalizando 28 recomendações. Entre estas, 8 eram para que a criança mamasse sentada no colo, outras 8 para que não adormecesse mamando e 12 a respeito do uso da mamadeira sem açúcar ou em pouca quantidade, sendo uma, ou mais, orientação dada pelo mesmo profissional.

A dieta inicial do lactente seja no seio, em mamadeira ou mista, contém suficiente açúcar sob a forma de lactose, podendo em situações desfavoráveis exercer efeito cariogênico. Certas práticas alimentares, tais como deixar a criança adormecer mamando (no seio materno ou com uma mamadeira que contenha outro líquido que não água), passar a chupeta no mel ou açúcar, podem induzir à cárie rampante - um tipo grave de cárie dental, com grandes destruições em um período pequeno de tem$\mathrm{po}^{28}$. Há relatos na literatura que a mesma destruição pode ser observada em crianças com alta freqüência de amamentação no seio materno por períodos muito prolongados de tempo, e, inclusive quan-

Tabela 1 - Abordagens com conotações preventivas para a saúde bucal dentro do item aleitamento.

\begin{tabular}{|c|c|c|c|c|c|}
\hline \multirow[t]{2}{*}{ Abordagem do profissional } & \multicolumn{2}{|c|}{ Total } & \multirow[t]{2}{*}{$\begin{array}{c}\text { Tipo de orientação } \\
\text { (uma ou mais por profissional) }\end{array}$} & \multicolumn{2}{|c|}{ Total } \\
\hline & Absoluto & Relativo & & Absoluto & Relativo \\
\hline \multirow{3}{*}{ Positiva } & \multirow{3}{*}{21} & \multirow{3}{*}{$43,7 \%$} & Não adormecer mamando & 8 & $38,1 \%$ \\
\hline & & & $\begin{array}{l}\text { Usar mamadeira com pouco } \\
\text { ou sem açúcar }\end{array}$ & 12 & $57,1 \%$ \\
\hline & & & Mamar sentada & 8 & $38,1 \%$ \\
\hline
\end{tabular}

Não relatada

$-$


do a mãe dorme com a criança mamando em seu seio durante a noite ${ }^{8,21,27}$.

Fraiz $^{11}$ (1993) observou que $90 \%$ das crianças que realizavam o aleitamento materno dormiam com a mãe ou eram retiradas do seio adormecidas, e 67,2\% das que usavam mamadeira dormiam com ela, mamando quando queriam, ou então a mamadeira era retirada após a criança adormecer.

Schuwartz e col. ${ }^{29}$ (1993), estudando crianças de até 8 anos de idade, observaram que 56\% delas eram colocadas para dormir com a mamadeira e destas, $70 \%$ adormeciam com ela. Das crianças que dormiam com a mamadeira, $62 \%$ apresentavam cárie enquanto entre as que tinham a mamadeira retirada antes de adormecer, $27 \%$ a apresentavam.

Vianna e col. ${ }^{32}$ (1971) mostraram que o leite mesmo, sem a adição de carboidratos, pode produzir in vitro cárie dental. O leite bovino puro produz menor desmineralização, seguido, em ordem crescente, pelo leite formulado especialmente para bebês, leite humano e leite associado ao mel.

Isto posto, o pediatra poderia orientar a mãe para que a criança não fosse alimentada deitada a fim de diminuir a estagnação de líquidos na cavidade bucal; bem como recomendar a higiene após a amamentação, além da não colocação de açúcar quando possível, pois este sem dúvida é o maior agravante nos casos de cárie rampante.

Os 21 profissionais estudados que abordaram os aspectos odontológicos do aleitamento, representam um número baixo $(43,7 \%)$ quando comparado aos $94 \%$ de pediatras que discutem a amamentação e o desmame com seus pacientes, conforme estudo de Koranyi e col. ${ }^{21}$, em 1991, nos EUA.

Apenas 22,9\% dos médicos relataram que o leite materno deve ser retirado aos 12 meses e o restante não fez referência. Koranyi e col. ${ }^{21}$ (1991) em seu estudo dizem que $80 \%$ dos profissionais mencionam que o desmame deve ser iniciado entre 12,7 e 16,8 meses.

Relacionando aspectos psicológicos e desmame, Johnsen ${ }^{18}$ (1991) comenta que este pode ser mais fá- cil por volta dos 6 meses do que aos 10, pois a partir daí a criança faz maior associação entre a alimentação e o prazer de mamar ao seio, tornando mais difícil a retirada. A Associação Americana de Pediatria ${ }^{21}$ recomenda o início do desmame aos 9 meses aproximadamente. No Brasil, o Ministério da Saúde veicula campanha na televisão recomendando amamentação materna até 2 anos de idade, ficando ainda mais evidente a necessidade de se orientar a prevenção de cáries dentais e problemas de oclusão.

$\mathrm{Na}$ Tabela 2, pode-se observar que $14,5 \%$ dos entrevistados recomendam retirar a mamadeira aos 24 meses, 8,3\% admitem até 36 meses. O restante não fez comentários quanto a época. Somente um profissional comenta a dificuldade de aceitação por parte dos pais da retirada da mamadeira aos 12 meses.

Tabela 2 - Recomendações sobre a época de retirada da mamadeira.

\begin{tabular}{lcc}
\hline \multirow{2}{*}{ Época } & \multicolumn{2}{c}{ Total } \\
\cline { 2 - 3 } & Absoluto & Relativo \\
\hline 2 anos & 7 & $14,5 \%$ \\
3 anos & 4 & $8,3 \%$ \\
Não relatada & 37 & $77,2 \%$ \\
\hline
\end{tabular}

Em relação à retirada da mamadeira, Shelton e Ferreti $^{30}(1982)$ recomendam que seja feita até os 12 meses e que, se isto for difícil, o seu conteúdo deve ser gradativamente diluído em água.

O segundo item questionado foi sobre dieta, onde se percebeu um comportamento relativamente homogêneo. O leite materno é recomendado até os 6 meses de idade, com introdução de frutas (papas ou sucos) por volta dos 3 meses. A introdução da papa salgada no almoço é recomendada entre 5-7 meses e no jantar entre 7-8 meses. Como sobremesa, suco ou fruta. Após um ano é orientada a alimentação normal da família.

Nesta questão, foram obtidas 18 respostas positivas de 13 médicos $(27,1 \%)$ (Tabela 3$)$. O restante dos entrevistados não fez nenhuma menção de orientação sobre saúde bucal (abordagem omissa).

Tabela 3 - Orientações relativas a recomendação sobre a dieta das crianças.

\begin{tabular}{|c|c|c|c|c|c|}
\hline \multirow{2}{*}{ Abordagem do profissional } & \multicolumn{2}{|c|}{ Total } & \multirow{2}{*}{$\begin{array}{c}\text { Tipo de orientação } \\
\text { (uma ou mais por profissional) }\end{array}$} & \multicolumn{2}{|c|}{ Total } \\
\hline & Absoluto & Relativo & & Absoluto & Relativo \\
\hline \multirow{3}{*}{ Positiva } & & & Evitar balas, chicletes, geléias & 6 & $46,2 \%$ \\
\hline & 13 & $27,1 \%$ & $\begin{array}{l}\text { Não ingerir alimentos nos } \\
\text { intervalos das refeições }\end{array}$ & 3 & $23,1 \%$ \\
\hline & & & $\begin{array}{l}\text { Comida progressivamente } \\
\text { mais sólida }\end{array}$ & 9 & $69,2 \%$ \\
\hline Não relatada & 35 & $72,9 \%$ & - & - & - \\
\hline
\end{tabular}


Segundo à literatura, a mais importante consideração para a saúde dentária é a freqüência de consumo de carboidratos por dia e a retenção bucal dos alimentos ingeridos, e não sua quantidade total consumida $^{16,23}$. As técnicas alimentares impróprias devem ser desestimuladas. À medida que a criança progride para alimentos mais sólidos, os lanches com componentes cariogênicos devem ter freqüência limitada.

A necessidade de uma alimentação progressivamente mais sólida, relatada por alguns profissionais, reflete uma possível preocupação com o desenvolvimento crânio-facial.

Em relação à higiene bucal, o principal aspecto abordado pelos entrevistados foi o início da escovação; $8,4 \%$ deles indicavam a necessidade de higienização antes do primeiro dente, em concordância com a literatura ${ }^{2,16,21}$. A maioria $(56,2 \%)$ respondeu que a escovação deve ser iniciada com a erupção dos dentes, $16,6 \%$ aos 2 anos de idade e 4,2\% somente aos 3 anos; $12,5 \%$ dos profissionais não fizeram referência à época, e somente $2,1 \%$ não responderam à questão (Tabela 4).

Tabela 4 - Orientação sobre o início da higiene oral.

\begin{tabular}{lrr}
\hline \multirow{2}{*}{ Época } & \multicolumn{2}{c}{ Total } \\
\cline { 2 - 3 } & Absoluto & Relativo \\
\hline Antes da erupção dos dentes & 4 & $8,4 \%$ \\
À erupção do $1^{\circ}$ dente & 27 & $56,2 \%$ \\
Aos 2 anos & 8 & $16,6 \%$ \\
Aos 3 anos & 2 & $4,2 \%$ \\
Não mencionada & 6 & $12,5 \%$ \\
Questão não respondida & 1 & $2,1 \%$ \\
\hline
\end{tabular}

Os presentes resultados são animadores, comparando-se com as observações de Koranyi e col. ${ }^{21}$ (1991), onde, embora 91,3\% façam alguma orientação de higiene, apenas $15 \%$ recomendam que seja iniciada logo após a erupção do primeiro dente.

Somente $12,5 \%$ dos médicos mencionaram o fio dental, variando a indicação do início de uso desde doze meses até 10 anos de idade.

Das respostas quanto ao item flúor, 58,3\% fizeram referência ao método sistêmico; $18,8 \%$ prescrevem flúor sistêmico e 39,5\% são contrários à sua administração. Destes que são contrários, $29 \%$ salientam que é devido à presença do flúor na água de abastecimento da cidade. Quanto ao método de flúor tópico, $25 \%$ recomendam a sua aplicação com o dentista, dentre estes, $4,2 \%$ recomendam a combinação do método tópico mais o sistêmico; $12,5 \%$ relataram usar flúor sem especificar o tipo; e 4,2\% não responderam a questão (Tabela 5).
Tabela 5 - Respostas obtidas sobre a prescrição do flúor.

\begin{tabular}{lrr}
\hline \multirow{2}{*}{ Método } & \multicolumn{2}{c}{ Total } \\
\cline { 2 - 3 } & Absoluto & Relativo \\
\hline Favorável ao flúor sistêmico & 9 & $18,8 \%$ \\
Contrário ao flúor sistêmico & 19 & $39,5 \%$ \\
Recomendam flúor tópico & 12 & $25,0 \%$ \\
Não mencionado & 6 & $12,5 \%$ \\
Questão não respondida & 2 & $4,2 \%$ \\
\hline
\end{tabular}

Diversos autores salientam a importância do flúor na água de abastecimento para a redução da incidência da cárie dental ${ }^{1,16,23,30}$, sendo que, se presente, este deveria ser o único método sistêmico, não devendo ser receitado nenhuma complementação, a qual poderia acarretar fluorose dentária ${ }^{17}$. Este fator deve ser cuidadosamente observado, pois no Município de São José dos Campos existe água fluoretada há aproximadamente 20 anos e ainda assim alguns profissionais continuam recomendando flúor sistêmico.

Portanto, antes de prescrever os suplementos de flúor, é essencial que seja determinado o conteúdo de flúor na água que a criança consome, considerando todas as fontes, de acordo com Griffen e Goepferd $^{16}$ (1991), Josell e Abrams ${ }^{19}$ (1982), Miller e Rosenstein ${ }^{23}$ (1982).

Nada foi comentado a respeito de uso de dentifrícios fluoretados, que também devem ser usados com cautela, pois Osuji e col. ${ }^{25}$ mostram que nas cidades com água fluoretada a maior incidência de fluorose dentária ocorre em crianças que começaram a usar as pastas muito precocemente, posto que nesta idade ingerem grande parte dos dentifrícios, como já foi demonstrado por Ericsson e Forsman ${ }^{10}$ (1969) e Barnhat e col. ${ }^{3}$ (1974).

No presente estudo questionou-se quais eram as orientações sobre o uso da chupeta, visando ao desenvolvimento da oclusão. Os resultados estão expressos nas Tabelas 6 e 7. De todos os profissionais estudados, $35,4 \%$ orientam que o uso da chupeta deve ser evitado ou o mais restrito possível (no momento de dormir, sendo retirada logo que a criança adormeça), embora não se referissem à época de retirada. Cerca de $50 \%$ aceitam seu uso sem restrições, sendo que destes, 37,5\% indicam a retirada aos 12 meses; $45,8 \%$ aos 24 meses e 16,7\% no máximo aos 36 meses. Do restante, $10,4 \%$ relataram não dar qualquer tipo de orientação e 4,2\% não comentaram o assunto. A respeito do tipo de chupeta, apenas $25 \%$ dos profissionais fizeram menção à chupeta ortodôntica.

Os estudos que documentam a prevalência da maloclusão e a necessidade de tratamento ortodôntico em crianças, variam na dependência dos critérios diagnósticos ${ }^{4}$ Kamp $^{20}$ (1991) estudou crianças de 6 a 52 meses e encontrou 6,3\% de pacientes com 
Tabela 6 - Condutas sobre o uso da chupeta.

\begin{tabular}{lcc}
\hline \multirow{2}{*}{ Características } & \multicolumn{2}{c}{ Total } \\
\cline { 2 - 3 } & Absoluto & Relativo \\
\hline Uso sem restrição & 24 & $50,0 \%$ \\
Uso mais restrito possível & 17 & $35,4 \%$ \\
Não orientam & 5 & $10,4 \%$ \\
Questão não respondida & 2 & $4,2 \%$ \\
\hline
\end{tabular}

Tabela 7 - Idade de retirada da chupeta, segundo os que não restringem seu uso.

\begin{tabular}{lcc}
\hline \multirow{2}{*}{ Idade } & \multicolumn{2}{c}{ Total } \\
\cline { 2 - 3 } & Absoluto & Relativo \\
\hline 1 ano & 9 & $37,5 \%$ \\
2 anos & 11 & $45,8 \%$ \\
3 anos & 4 & $16,7 \%$ \\
\hline
\end{tabular}

maloclusão, sendo que a mordida cruzada era a mais prevalente. Neste mesmo estudo, Kamp, citando Musselmann $^{24}$ (1981), relata que $95 \%$ das crianças abaixo de 4 anos têm o hábito de sugar o dedo ou a chupeta.

Black e col. ${ }^{5}$ (1980) relatam que os hábitos de sucção nocivos (dedos e chupetas) têm sido atribuídos à atividade de sucção em uma alimentação inadequada, por um período de tempo prolongado. Pode haver frustação do bebê no instinto da sucção pela sua retirada imediata do seio após a amamentação ou pelo uso da mamadeira, uma vez que a criança não permanece sugando após o término de seu conteúdo. Se o bebê chora apesar de bem alimentado, a reação natural mais observada é colocação da chupeta para mantê-lo tranqüilo. Isto pode resultar numa criança treinada inadvertidamente para buscar a gratificação oral. Assim o ideal seria o médico orientar quanto à técnica de amamentação adequada, não retirando a criança do seio rápido demais, permitindo assim que ela satisfaça sua necessidade de sucção. Se não houver como evitar o uso da chupeta, indicar a ortodôntica, pois permite posicionamento correto da língua e um vedamento labial adequado ${ }^{5}$.

Quanto à preocupação com o efeito da mamadeira no desenvolvimento da oclusão, apenas $4,2 \%$ fazem referência ao tipo de bico desta, que deve ter furo pequeno e formato anatômico. Isto é bastante importante, pois a deglutição atípica tem sido atribuída à alimentação com mamadeira com bicos longos e orifícios aumentados, onde o líquido é retirado pelo pressionamento posterior impedindo a sucção anterior e tornando os lábios hipofuncionais durante o ato 5 .

Garliner $^{12}$ (1984) orienta que o comprimento, a flexibilidade e o fluxo devem ser levados em consideração quando da escolha do bico da mamadeira: deve ter comprimento adequado ao tamanho da boca da criança, flexibilidade suficiente para que ela pos- sa manipulá-lo com a língua e possibilidade do controle do fluxo com seus músculos faciais. E ainda afirma que o sistema de amamentação escolhido terá um papel importante no eventual desenvolvimento facial da criança.

A última questão foi a respeito do encaminhamento dos pacientes ao dentista, se é feito, em qual faixa etária ou em que situação. Griffen e Goepferd ${ }^{16}$ (1991), recomendam que a criança seja levada ao dentista dentro de 6 até 12 meses, após a erupção do primeiro dente, para que sejam dadas as devidas orientações.

No presente estudo, $10,4 \%$ dos profissionais orientam que a primeira visita deve ser feita assim que aparece um dente até no máximo 18 meses após. A maioria $(54,2 \%)$ indica a faixa de $2-3$ anos para a visita; $10,4 \%$ entre $4-5$ anos, e $4,2 \%$ orientam somente na fase escolar por volta de 7 anos. Cerca de $18,7 \%$ dizem que encaminham mas não mencionam a idade. Apenas um médico respondeu que não encaminha seus pacientes $(2,1 \%)$ (Tabela 8$)$.

Tabela 8 - Orientação sobre encaminhamento ao dentista.

\begin{tabular}{lrr}
\hline \multirow{2}{*}{ Época } & \multicolumn{2}{c}{ Total } \\
\cline { 2 - 3 } & Absoluto & Relativo \\
\hline Após o $1^{\circ}$ dente até 1,5 anos & 5 & $10,4 \%$ \\
Dos 2-3 anos & 26 & $54,2 \%$ \\
Dos 4-5anos & 5 & $10,4 \%$ \\
Aos 7 anos (escolar) & 2 & $4,2 \%$ \\
Não mencionada & 9 & $18,7 \%$ \\
Não encaminha & 1 & $2,1 \%$ \\
\hline
\end{tabular}

Diante de um quadro estabelecido de maloclusão, cárie ou outras alterações, 52,8\% dos profissionais dizem orientar a ida da criança ao dentista. Destes, $10,4 \%$ fazem o encaminhamento somente nessas condições.

Sem dúvida, o ideal seria a indicação precoce ao dentista, antes da erupção do primeiro dente. Já que esta situação nem sempre é possível, seria importante que o próprio pediatra oferecesse algumas orientações. Muitos problemas poderiam ser minimizados com o auxílio do médico, ainda mais num país pobre como o Brasil, onde é muito mais difícil o acesso da criança em idade precoce ao dentista do que ao médico.

\section{COMENTÁRIOS FINAIS}

Acreditando que seria de grande valia a participação do médico pediatra na manutenção saúde bucal, comentam-se a seguir, alguns tópicos julgados importantes. 


\section{Quanto à Amamentação}

Estimular o aleitamento materno. Quando necessário o uso da mamadeira, desestimular a adição de açúcar (no leite, suco, chá, etc.). Alimentar a criança sentada no colo, nunca deitada no berço. Após a erupção do primeiro dente desestimular a alimentação durante o sono. Enquanto esta não for totalmente eliminada, higienizar com gaze ou fralda úmida após a mamada.

\section{Quanto à Dieta}

Estabelecer hábitos saudáveis para a dieta. Manter disciplina de horário das refeições e lanches para evitar que a criança fique comendo fora de hora. Recomendar que a ingestão de doces deve ser feita na sobremesa, quando há um aumento do fluxo salivar e a criança escovará os dentes em seguida. Evitar passar os alimentos no liquidificador, se necessário amassar com o garfo.

\section{Quanto à Higiene Bucal}

Iniciar a higiene bucal antes da erupção dos dentes, com fralda ou gaze úmida. Após a erupção dos dentes, quando a criança mamar, sempre realizar a limpeza com a fralda. Iniciar a escovação dos dentes com uma escova macia e de pequeno tamanho, o mais precocemente possível. Nesta fase, usar pouco ou nenhum dentifrício, tomando cuidado para que as crianças não ingiram a espuma.

\section{Quanto à Chupeta ou Bico de Mamadeira}

Para evitar o uso da chupeta, recomendar a técnica correta de amamentação, não retirando a criança do seio logo que já esteja satisfeita, em especial se ela continuar sugando. A chupeta só é indicada quando mesmo após sugar bastante no seio, ela continuar com necessidade de sucção. Neste caso, devese recomendar a chupeta ortodôntica, orientando quanto a posição correta da mesma.

Recomendar bico de mamadeira curto e com orifício pequeno e orientar para que a mãe não aumente o furo para dar alimentos mais espessos. Estes devem ser oferecidos com colher. A mamadeira deve ser retirada por volta dos 12 meses, oferecendo líquidos no copo. Como recurso auxiliar, pode-se usar copos com bicos especiais ou com canudos, assim que a criança aprender a chupar.

\section{REFERÊNCIAS BIBLIOGRÁFICAS}

1. ABRAMS, R.G. \& JOSELL, S.D. The role of pediatrician in oral health care. Pediat. Clin. N. Am., 38:1049-52, 1991.

2. AMERICAN DENTAL ASSOCIATION. Guide to the dental health. Parents: questions and answers. J. Am. Dent. Ass., (Spec. iss ):19-29, 1987.

\section{Quanto ao Flúor}

A sua prescrição por via sistêmica não se justifica, se na cidade houver flúor na água de abastecimento em concentrações ideais. Deve-se também alertar quanto aos dentifrícios que devem ser utilizados em pequenas quantidades e sob supervisão dos pais. Sua ingestão excessiva, dependendo da idade da criança pode causar fluorose dentária, se houver água fluoretada na rede de abastecimento.

\section{Quanto ao Encaminhamento dos Pacientes ao Dentista}

Sendo possível, deve ser feito antes da época de erupção dos dentes para que o dentista oriente sobre dieta e higiene bucal adequada e dê as explicações necessárias à mãe sobre outras medidas preventivas, como uso do selante e aplicações tópicas de flúor.

Concordando com Elvey e Hewie ${ }^{9}$ (1982), sugere-se maior inter-relacionamento entre as áreas médica e odontológica, devido ao fato de que muitos dos hábitos alimentar e de sucção inadequados podem ser adquiridos antes mesmo de os dentes irromperem. Neste contexto, o profissional de odontologia poderia auxiliar no diagnóstico de algumas doenças sistêmicas que apresentam suas manifestações mais precoces na cavidade bucal, além de o médico pediatra poder ajudar na prevenção de doenças bucais, orientando e encaminhando àquele profissional seus pacientes, precocemente.

\section{CONCLUSÃO}

Finalmente conclui-se numa primeira avaliação, que a freqüência das condutas dos médicos pediatras em relação à saúde bucal foi baixa. Há necessidade da introdução de seminários e palestras sobre saúde bucal dentro da formação do médico pediatra, para garantir que tais condutas se tornem rotina.

Mais estudos na área são necessários para identificar as reais carências da relação do médico pediatra e odontopediatra, nos dois sentidos da mesma, para que as crianças tenham maiores chances de se desenvolverem em boas condições de saúde geral e bucal.

3. BARNHART, W.E.; HILLER, L.K.; LEONARD, G.J.; MICHAELS, S.E. Dentifrice usage and ingestion among four age groups. J. Dent. Res., 53:1317-22, 1974.

4. BLACK, B. Deglutição atípica. Atual. Otolog. Foniatr., 5:90-2, 1980. 
5. BLACK, B.; KOVESI, E.; CHUSID, I. J. Hábitos bucais nocivos. Ortodontia (S.Paulo), 23:40-4, 1990.

6. BROWN, J.P.; JUNNER, C.; LIEW, V. A study of Streptococcus mutans levels in both infants with bottle caries and their mothers. Aust. Dent. J., 30:96-103, 1985.

7. COLLEY, R.O. \& SANDERS, B.J. The pediatrician's involviment in prevention and treatment of oral disease in medically compromissed children. Pediat. Clin. N. Am., 38:1265-88, 1991.

8. DELGADO RODRIGUES, C.M.; PORDEUS, L.A.; ANDO, T. Cáries extensas em dentes decíduos por aleitamento materno prolongado. Encicl. Bras. Odont., 4:97-103, 1986.

9. ELVEY, S.M. \& HEWIE, S.P. The pediatrician's dental evaluation. Pediat. Clin. N. Am., 29:761-9, 1982.

10. ERICKSSON, Y. \& FORSMAN, B. Fluoride retained from mouthrinses and dentifrices in preschool children. Caries Res., 3:290-9, 1969.

11. FRAIZ, F.C. Estudo das características de utilização de açúcar através da mamadeira, do primeiro contato com o açúcar e do padrão de aleitamento em crianças de 0 a 36 meses, Curitiba. São Paulo, 1993. [Dissertação de Mestrado - Faculdade de Odontologia da USP].

12. GARLINER, D. Facts that every mother should know when choosing an artificial nursing system for her child. Int. J. Orthodont., 22:18-20, 1984.

13. GLEISER, R. \& CZLUSNIAK, G.D. Cárie de mamadeira. Odont. Mod., 11:20-4, 1984.

14. GOEPFERD, S.J. Infant oral health: a rationale. J. Dent. Child., 53:257-60, 1986.

15. GREENE, J.C. A primeira dentição: base para saúde oral. Saúde do Mundo (dez.):6-9, 1973.

16. GRIFFEN, A.L. \& GOEPFERD, S.J. Preventive oral health care for the infant, child and adolescent. Pediat. Clin. N. Am., 38:1209-26, 1991.

17. GUEDES-PINTO, A.C. Odontopediatria. São Paulo, Santos Editora, 1990.

18. JOHNSEN, D.C. The role of pediatrician in identifying and treating dental caries. Pediat. Clin. N. Am., 38:1173-81, 1991.

19. JOSELL, S.D. \& ABRAMS, R.G. Common oral and dental emergencies and problems. Pediat. Clin. N. Am., 29:681$715,1982$.

20. KAMP, A.A. Well-baby dental examinations: a survey of preschool children's oral health. Pediat. Dent., 13:86-90, 1991.
21. KORANYI, K.; RASNAKE, L.K.; TARNOWSKI, K.J. Nursing bottle weaning and prevention of dental caries: a survey of pediatricians. Pediat. Dent., 13:32-4, 1991.

22. MARINO, R.V.; BOMZE, K.; SCHOOL, T.O.; ANHALT, H. Nursing botlle caries: characteristics of children of risc. Clin. Pediat. (Philadelphia), 28:129-31, 1989.

23. MILLER, R.E. \& ROSENSTEIN, D.J. Children's dental health: overview for the physician. Pediat. Clin. N. Am., 29:429-32, 1982.

24. MUSSELMAN, R.J. apud KAMP, A.A. Well-baby dental examinations: a survey of preschool children's oral health. Pediat. Dent., 13:86-90, 1991.

25. OSUJI, O.O.; LEAKE, J.L.; CHIPMAN, M.L.; NIKIFOROF, G.; LOCKER, D.; LEVINE, N. Risk factors for dental fluorosis in a fluoridated community. J. Dent. Res., 67:1488-92, 1988.

26. RAZUK, E.D. apud GALVÃO, S. Boa escovação evita surgimento de gengivites. O Estado de São Paulo, São Paulo, 09 de jan. de 1994. p. A25.

27. RIPA, L.W. Nursing caries: a comprehensive review. Pediat. Dent., 10:268-82, 1988.

28. SCHUMAN, N.J. \& MILLS, J.A. A strategy for decreasing the incidence of baby bottle syndrome. J. Tenn. Dent. Ass., 61:22-4, 1981.

29. SCHUWARTZ, S.S.; ROSIVACK, R.G.; MICHELOTTI, P. A child's slepping habit as a cause of nursing caries. J. Dent. Child., 69:22-5, 1993.

30. SHELTON, P.G. \& FERRETTI, G.A. Maintaining oral health. Pediat. Clin. N. Am., 29:653-68, 1982.

31. THYLSTRUP, A. \& FEJESKOV, O. Tratado de cariologia. Rio de Janeiro, Cultura Médica, 1988.

32. VIANNA, R.B.; KATZ, S.; ROCHE, I.R. apud DELGADO RODRIGUES, C.M.; PORDEUS, L.A.; ANDO, T. Cáries extensas em dentes decíduos por aleitamento materno prolongado. Encicl. Bras. Odont., 4:97-103, 1986.

33. WALTER, L.R.F. \& NAKAMA, L. Paciente de alto índice de cárie x paciente de alto risco. Qual a conduta? In: Atualização na clínica odontológica. São Paulo, Artes Médicas, 1992. p.251-8.

34. WALTER, L.R.F.; FERELLE, A.; HOKAMA, N.; PELANDA, V.L.G.; FRANCO, M.P.S.; IEGA, R. Cárie em criança de 0 a 30 meses de idade e sua relação com hábitos alimentares. Encicl. Bras.Odont., 5:129-36, 1987. 